\title{
DESARROLLO PERSONAL Y PRÁCTICA ESPIRITUAL: ANÁLISIS NARRATIVO DE VIVENCIAS
}

\section{PERSONAL DEVELOPMENT AND SPIRITUAL PRACTICE: NARRATIVE ANALYSIS OF EXPERIENCES}

\author{
Asun Puche Echegaray \\ Facultat de Psicologia, Ciències de l'Educació i l'Esport Blanquerna \\ Universidad Ramon Llull. Barcelona. España \\ ORCID: https://orcid.org/0000-0002-2329-780X \\ Luis Botella García del Cid \\ Facultat de Psicologia, Ciències de l'Educació i l'Esport Blanquerna \\ Universidad Ramon Llull. Barcelona. España \\ ORCID: https://orcid.org/0000-0003-3794-5967
}

Cómo referenciar este artículo/How to reference this article:

Puche, A. y Botella, L. (2020). Desarrollo Personal y Práctica Espiritual: Análisis Narrativo de Vivencias. Revista de Psicoterapia, 31(117), 57-83. https://doi.org/10.33898/rdp.v31i117.449

\begin{abstract}
Resumen
El objetivo de este trabajo es adentrase en la vivencia espiritual y contribuir a la comprensión de los efectos que aporta la práctica espiritual. El estudio se abordó desde el estudio de dos prácticas espirituales de la tradición cristiana: los Ejercicios Espirituales de San Ignacio de Loyola -una práctica intensiva de un mes de duración- y los Ejercicios de Contemplación del jesuita Franz Jalics, de 8 días. El método desarrollado fue un análisis narrativo exhaustivo de las experiencias en primera persona de diez participantes en dichos ejercicios espirituales. Los resultados hallados se presentan en forma de mapa conceptual y en macrocategorías de significado de la experiencia. El análisis dio lugar a la emergencia de un concepto nuclear al que denominamos Sensibilidad Espiritual, y para el que propusimos una definición a partir de las categorías halladas. Como conclusión se apunta hacia una psicología contemplativa, enfocada hacia la dimensión espiritual y contemplativa del ser humano y de los procesos que facilitan dicha dimensión.

Palabras clave: Espiritualidad, Ejercicios Espirituales Ignacianos, Ejercicios de Contemplación, Prácticas contemplativas, Sensibilidad Espiritual, Narrativas.

Abstract

The goal of this study is to study thoroughly in the lived spiritual experience, and to contribute to the understanding of the effects that the spiritual practice brings forth. Specifically, the study addressed the analysis of two spiritual practices from the Christian tradition. The Spiritual Exercises of Saint Ignatius of Loyola -an intensive month-long practice- and the Contemplative Retreat of the Jesuit Franz Jalics. The method employed a detailed narrative analysis of the first person accounts of ten participants in the mentioned spiritual practices. The findings were presented in the form of conceptual map and in macro-categories of the meaning of the experience. The analysis brought up the emergence of a nuclear concept that we called Spiritual Sensitivity, and to which we proposed a definition based on the categories previously found. As a conclusion, we point to the emergence of a contemplative psychology, focused on the spiritual and contemplative dimension of the human being and on the processes that facilitate this dimension.

Keywords: Spirituality, Ignatian Spiritual Exercises, Contemplative Retreat, Contemplative Practices, Spiritual Sensitivity, Narratives.

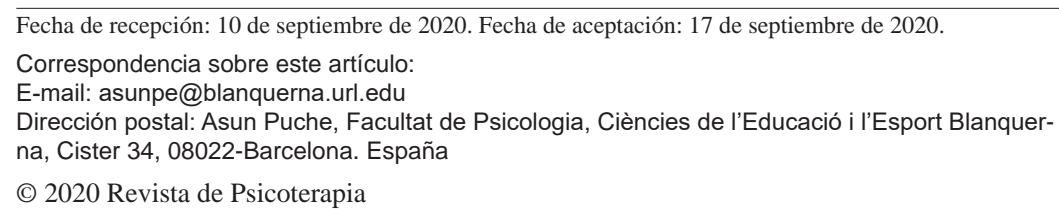


En los últimos años se ha ido haciendo más explícita la colaboración entre la psicología y la espiritualidad, como lo demuestra el creciente interés de los temas convergentes entre ambos campos.

Este interés queda reflejado en el desarrollo de nuevos modelos conceptuales y aplicados que integran en sus planteamientos la dimensión trascendente de la persona -que tradicionalmente había sido considerada desde el ámbito de la espiritualidad-como ha sido el caso de la psicología transpersonal.

Abraham Maslow propuso el término transpersonal para designar lo que se consideró un nuevo modelo de psicología que estudiaba y promovía experiencias, fenómenos y "estados de conciencia trascendentes, espirituales y unificadores" (Lajoie y Shapiro, 1992, p. 91).

El objetivo principal de la psicología transpersonal es que los seres humanos trasciendan el sentido de sí mismos la identificación con el cuerpo y la mente -para llegar a identificarse con una conciencia mayor (Groff, 2000; Maslow, 1972; Wilber, 1989).

Este modelo ha puesto en diálogo la práctica psicológica clínica con principios de las tradiciones espirituales (véase, por ejemplo, Almendro, 1995; Braud y Anderson, 1998; Groff, 1986).

Por otro lado, cada vez se está profundizando más en el estudio de los efectos de diferentes prácticas de meditación - procedentes de tradiciones espirituales-así como en su aplicación en contextos psicoterapéuticos (véase, por ejemplo, Schreurs, 2004; Wellwood, 2002). En concreto, el concepto de mindfulness -traducible por conciencia plena-y que procede del budismo está siendo incorporado en investigaciones científicas de campos interdisciplinarios como son las ciencias de la salud, las neurociencias y las ciencias cognitivas.

Así se investiga sobre mindfulness en relación a la reducción del estrés (Grossman et al., 2004; Kabat-Zinn et al., 1992) en comportamientos adictivos de abuso de substancias (Leigh et al., 2005); en pacientes con depresión tratados desde modelos cognitivos (Ramel et al., 2004; Scherer-Dickson, 2004; Segal et al., 2002; Teasdales et al., 2000); y en nuevas corrientes de terapia conductual (Hayes et al., 1999; Hayes, 2004; Hayes et al., 2006).

En nuestro contexto, por ejemplo, se editaron dos volúmenes monográfico sobre mindfulness y psicoterapia en la Revista de Psicoterapia, uno en el año 2006 y otro en 2016 coincidiendo con el décimo aniversario del primero, y algunos de sus artículos son de hecho los más leídos de la revista según sus propias estadísticas.

Así pues está dándose una convergencia entre prácticas procedentes de tradiciones espirituales y la psicología, tanto a nivel conceptual como aplicado. Específicamente, se trata de prácticas meditativas procedentes de oriente -principalmente del budismo, aunque también del hinduismo- a pesar de que la cultura occidental cuenta con una larga tradición contemplativa-procedente del cristianismo-práctica que se puede equiparar con el concepto de meditación oriental. 


\section{Campo Específico de la Experiencia Espiritual Objeto de Estudio}

Prácticas espirituales hay muchas, tantas como tradiciones y familias religiosas se han sucedido a lo largo de los tiempos.

Este trabajo se focaliza en dos de ellas, enmarcadas en la tradición cristiana, en concreto católica. No obstante, hoy en día, en la práctica, podemos encontrar en los grupos de practicantes a personas provenientes de otras tradiciones o familias religiosas, suficientemente abiertas para apreciar y aprovechar la sabiduría y los beneficios de estos caminos de crecimiento.

La primera son los Ejercicios Espirituales de San Ignacio de Loyola. La tradición cristiana dispone de la expresión "contemplativos en la acción”, que refleja el ideal o carisma propio de la espiritualidad ignaciana, a partir de la vivencia de San Ignacio de Loyola, fundador de la Compañía de Jesús, a la que pertenecen los Jesuitas. Contemplativo en la acción implica una actitud de contemplación continuada desde el propio actuar, en una dinámica permanente y circular en la que el actuar es asimismo generado desde el contemplar. Con una tradición ya secular, tal como hoy se presenta, se ha ido enriqueciendo con las aportaciones de diferentes ámbitos de las ciencias humanas.

La segunda son los Ejercicios de Contemplación, tal como son propuestos por el jesuita húngaro Franz Jalics. Basados en el silencio y la quietud y apoyados en la invocación del nombre de Jesús, esta práctica contemplativa cristiana se acerca a otras tradiciones contemplativas orientales.

\section{Participantes: Los Ejercitantes}

\section{Método}

Dada la elevada demanda de tiempo y esfuerzos requerida para el análisis individualizado, intensivo y exhaustivo de cada narrativa, y su gran dependencia en métodos cualitativos y de análisis de texto, así como debido a la propia naturaleza de la experiencia, el número de participantes se limitó a diez. Para la primera parte del estudio, referido a la vivencia de los Ejercicios Espirituales de San Ignacio, se dispuso de cuatro narrativas; tres de las cuales fueron reflexiones a posteriori, mientras que una cuarta persona entregó para el estudio su diario personal que escribía día a día acerca de su vivencia durante los 30 días de duración del retiro de Ejercicios Espirituales.

Para la segunda parte del estudio, se contó con seis narrativas de personas participantes en un retiro de Ejercicios de Contemplación de 8 días de duración siguiendo el modelo propuesto por Franz Jalics, sj. (1998).

Todos los participantes fueron voluntarios a quienes se les informó del estudio una vez finalizado el retiro y que desearon colaborar escribiendo su vivencia, según la pauta amplia que se les dio.

Como se ha mencionado, ambos retiros se realizaron en el Centro Internacional de Espiritualidad Cueva de San Ignacio, de Manresa, donde jesuitas y laicos colaboradores dan los dos tipos de retiros cada año. 
Presentamos brevemente a los ejercitantes que participaron en el trabajo.

Para el Estudio 1 del Mes de Ejercicios Espirituales de San Ignacio de Loyola se contó con la participación de tres mujeres, Esther, Alicia, Verónica y, un varón Arturo.

Ester tenía 27 años en el momento del retiro. Su atracción por la figura de Jesús de Nazaret "había ido creciendo y madurando, aumentando mis ganas de amarle y seguirle, y conduciéndome a realizar experiencias como ésta”. (Ester, 7-9).

Alicia, de 53 años, practicante de meditación zen, junto con sus prácticas como cristiana católica, deseó aclarar en su narrativa -en un pie de página- que "cuando decidí hacer el Mes de Ejercicios Espirituales la motivación era "poner orden”, ver si podría ser más consecuente en mi estilo de vida” (Alicia, 215, nota 2).

Verónica, de 34 años, religiosa en una congregación católica, misionera en África. En el primer día de su diario de Ejercicios Espirituales dejó anotado: “Llego a Manresa con el deseo de dejarme guiar por Él a través de todo, de entrar en ese nivel profundo del corazón y quedarme ahí”. (Verónica, 62-63).

Arturo, sacerdote diocesano que, con 64 años, inició la narrativa sobre su vivencia del Mes de Ejercicios Espirituales diciendo: "Participar en los Ejercicios Ignacianos en Manresa me ha marcado profundamente, es un hito en mi vida, hay un antes y un después”. (Arturo, 5-7).

Para el Estudio 2 de Ejercicios de Contemplación (8 días) se contó con la participación de 6 mujeres.

Begoña, de 48 años, había iniciado la práctica contemplativa según el modelo propuesto por Franz Jalics tres años atrás.

Carolina, de 51 años, iniciada en este modelo de práctica contemplativa un año atrás, si bien ya tenía experiencia anterior con otros tipos de prácticas contemplativas.

Gabriela, de 60 años. Su segundo año de retiro de ocho días de Ejercicios de Contemplación.

Mariluz, de 59 años, se inició en esta modalidad contemplativa tres años atrás.

Marta, de 54 años. Éste fue su cuarto retiro anual consecutivo de 8 días de Ejercicios de Contemplación.

Nerea, de 48 años, éste fue su primer retiro de esta modalidad.

Todas ellas se ejercitaban cada día en la práctica contemplativa entre 30 minutos y dos horas.

\section{Instrumentos: Las Narrativas}

El estudio contó con diez narrativas en primera persona acerca de la vivencia del retiro de Ejercicios producidas por los mismos participantes voluntarios. Estas narrativas fueron solicitadas como medio para acceder a su experiencia subjetiva o, más precisamente, al modo en que ellos la construyeron.

En la carta en que se solicitaba una colaboración voluntaria para este estudio se dio una indicación para la elaboración de su narrativa, y que en esencia se centraba en la vivencia del retiro espiritual y en lo que había significado en su vida. 
Reproducimos a continuación el fragmento en el que se halla dicha indicación (con ligeras modificaciones en el segundo estudio).

Indicación para la elaboración de la narrativa para los participantes de los Ejercicios Espirituales de San Ignacio:

En concreto, a efectos de tu experiencia te solicitamos lo siguiente:

Nos gustaría que reflexionaras por escrito sobre tu vivencia en el Mes de Ejercicios del pasado Julio incluyendo todos los aspectos que consideres necesario, y haciendo especial énfasis en lo que significa para ti y para tu vida. Hazlo con tanta extensión y profundidad como sientas necesario.

Indicación para la elaboración de la narrativa para los participantes de los Ejercicios de Contemplación:

La participación y colaboración consiste en describir por escrito la vivencia de los Ejercicios y la práctica contemplativa según se indica a continuación: Describe, en los términos y extensión que consideres oportunos, cuál/es ha/n sido tu/s vivencia/s de los Ejercicios de Contemplación (siguiendo el método Jalics) que acabas de realizar, incluyendo todas las dimensiones que quieras destacar. También, si lo deseas, puedes añadir cualquier cambio que consideres que la práctica contemplativa realizada de forma regular te haya aportado a nivel interior y/o en tu vida, así como describir tu vivencia personal sobre ello.

Asimismo, se les solicitó en este último caso, información contextual adicional referida al sexo, la edad, inicio de la práctica contemplativa según el modelo de Jalics, la frecuencia de la práctica, así como otro tipo de prácticas contemplativas o modos de oración que realizasen.

\section{Procedimiento: Categorización de Unidades de Análisis}

Tras haber compilado las narrativas en primera persona, éstas fueron analizadas siguiendo una metodología basada en el método cualitativo de Grounded Theory Methodology. Dado que una revisión exhaustiva de los fundamentos epistemológicos de dicha metodología va más allá de la finalidad de este artículo, remitimos al lector interesado al trabajo de Herrero (2003).

En síntesis, el método utilizado fue:

1. El texto se dividió en unidades de análisis (UAs) significativas. En este trabajo, se adoptó un criterio basado en la coherencia de contenido. A cada UA se le asignó un código numérico jerarquizado en orden decimal. Además, al final de cada UA aparece el nombre asignado a el/la autor/a de la narrativa de la que se trate, así como la/s línea/s de texto de la que se extrajo la UA.

2. El significado de cada UA se sintetizó en tantas categorías como fue necesario.

3. Las UAs se codificaron en estas categorías. Cada UA se codificó según su significado y fue asignada al menos a un nódulo de categoría. Eventualmente, el proceso entero se satura; es decir, la codificación no aporta ninguna otra categoría. El análisis se realiza mediante consenso entre investigadores. 
4. Las categorías se organizan jerárquicamente en forma de mapa conceptual. Este proceso es dialéctico en su propia naturaleza, ya que el mapa conceptual se va delimitando a medida que la avanza la codificación, y la codificación cambia según se va refinando el mapa. Del mismo modo que en el paso 3, eventualmente todo el proceso queda saturado; en este caso, una nueva codificación del texto no modifica la estructura del mapa conceptual.

\section{Aspectos Éticos: El Anonimato}

Dada la naturaleza de este trabajo, en el que nuestra aproximación fue a personas que ya habían realizado una experiencia determinada, las consideraciones éticas quedaron enfocadas a asegurar los siguientes aspectos: a) participación voluntaria e informada y b) garantizar el anonimato de los ejercitantes que compartieron por escrito sus vivencias de los retiros. Para ello, en la carta remitida a los ejercitantes solicitando su colaboración se explicó el modo en que se procedería.

Dando cumplimiento al principio del anonimato, los nombres de todos los participantes han sido cambiados. Asimismo, decidimos omitir el año del retiro tanto para el estudio del Mes de Ejercicios Espirituales como en el de Ejercicios de Contemplación de ocho días, con la intención y el deseo de extender aún más ese principio, dada la cercanía física del lugar en el que los ejercitantes llevaron a cabo los retiros, y el relativamente reducido número de personas que los realizan en cada tanda.

\section{Resultados e Interpretación}

\section{El Mes de Ejercicios Espirituales}

Dada la naturaleza de este trabajo, los resultados van íntimamente ligados a su interpretación. Elaborar categorías a partir de unidades de análisis es, en sí mismo, un modo de interpretar. Junto a Charmaz (2008) asumimos que "somos parte de los significados que observamos y definimos" (p. 90). Es por ello, que estos dos importantes elementos de la investigación han quedado explícitamente unidos en el encabezado de este apartado.

El resultado-interpretación de este estudio toma la forma de Mapa Conceptual que se fue desarrollando, según indicado en el apartado de procedimiento, siguiendo los pasos y la metodología propia de la Grounded Theory Methodology, incorporando procesos propios de las técnicas de análisis del discurso. En él se encuentran los diversos niveles de jerarquización y categorías en que fueron codificadas cada unidad de análisis, las líneas de texto de cada narrativa.

\section{Mapa Conceptual}

En base al análisis de los textos conjuntamente considerados emergieron siete categorías de estructura narrativa, cada una de las cuales incluye codificaciones de las vivencias experimentadas por los ejercitantes del Mes de Ejercicios Espirituales, siendo una de ellas comentarios reflexivos que surgieron durante la tarea de narrar 
su experiencia por escrito.

1. Información contextual

2. Estructura de las jornadas de Ejercicios Espirituales.

3. Comentarios reflexivos centrados en la propia tarea de narrar la experiencia de los Ejercicios Espirituales.

4. Vivencias de los Ejercicios Espirituales propiamente dicha.

5. Resumen sintético de la experiencia.

6. Valoración global de la experiencia.

7. Efectos post- de la experiencia.

Cada una de estas categorías nucleares albergaba otros niveles de categorías más cercanos a la experiencia directamente expresada en la narrativa. El número de línea(s) de la narrativa de dónde partió la categorización se indica junto al nombre del narrador.

Antes de proceder con la exposición del mapa conceptual, cabe precisar que el proceso de interpretación se inicia -empieza a asomar- en la forma del mapa conceptual, mas no concluye aquí. En el siguiente apartado titulado "El Árbol-Eje de la Vivencia” la interpretación prosigue y se adentra en la discusión del trabajo, tal y como se explicará.

\section{El Árbol-Eje de la Vivencia}

Una vez obtenido el mapa, en el que quedaron incluidas todas las líneas de texto de las narrativas, se inició una fase de adentramiento más profundo siempre con la intención de seguir indagando a partir de la pregunta originaria: ¿qué viven las personas que realizan una práctica espiritual intensiva?

El propio proceso de acercamiento sistematizado, de creación de categorías, de búsqueda de relaciones entre ellas, de aproximaciones a conceptos cada vez más englobantes, llevaba a regresar una y otra vez a la lectura-escucha cada vez más interiorizada-de los textos.

Finalmente, emergió un tronco común, como una columna vertebral que engarzaba las diversas formulaciones disponibles y que parecía sostener la comunalidad de la experiencia tal y como fue narrada.

Aquí aparecía una estructura de interpretación fruto del análisis exhaustivo dando coherencia, en una síntesis de significado, que contenía los elementos más relevantes, y cuyas categorías nucleares surgieron en forma de respuesta a preguntas. Preguntas que enmarcan el eje de la vivencia: "Entrar en una escuela de vida”. Preguntas que respondían a la clave de lectura, y que presentamos a continuación:

1. ¿De dónde parte?

2. ¿Con qué cuenta?

3. ¿Qué encuentra?

4. ¿A dónde lleva?

5. ¿Qué emerge?

Recorrer ese tronco común, abrir sus ramas, exponer sus hojas, mostrar sus 
frutos, y eventualmente penetrar y palpar sus raíces es la propuesta cuyo equivalente en terminología académica configura la interpretación y discusión de este trabajo.

A continuación, el tronco con sus ramas principales.

1. ¿¿De dónde parte?

a. La experiencia: El Mes de Ejercicios Espirituales de san Ignacio de Loyola

b. ¿Cómo se llega? Disposición al inicio y experiencias previas

2. ¿Con qué cuenta? (Elementos de apoyo en el proceso)
a. En retiro y en silencio
b. Método y estructura
c. Acompañamiento
d. El grupo
e. Los espacios: capillas, jardín, dormitorio, sala de puntos
f. Ejercicios y prácticas cinéticas: Chi-Kung
g. Alimentación
h. Actividades guiadas de mediodía

3. ¿Qué encuentra?
a. Auto-descubrimiento: el encuentro con la propia realidad
b. Aumento de la conciencia
c. Una nueva conciencia del cuerpo
d. Experiencias unitivas: la relacionalidad

4. ¿A dónde lleva?
a. Aceptación
b. Crecimiento
c. Integración
d. Cambios en la vida

5. ¿Qué emerge?: El horizonte del nuevo self
a. Libertad
b. Entrega (servicio)
c. Conciencia de unidad
d. Actuar desde el ser: contemplativos en la acción

Figura 1. Cuerpo de los Efectos Hallados

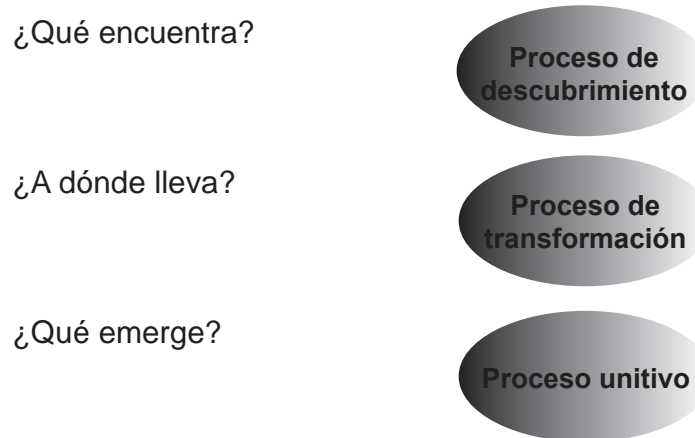


Las dos primeras preguntas -clave de lectura-proporcionan información sobre el método, en concreto el punto de partida de los ejercitantes y los elementos de apoyo propios de la práctica espiritual en este estudio considerada.

Las tres preguntas siguientes: ¿qué encuentra?, ¿adónde lleva? y ¿qué emerge? constituyen el cuerpo de los efectos hallados de la práctica de Ejercicios Espirituales (Figura 1). De aquí emergieron 12 categorías nucleares que respondían a las preguntas que han enmarcado el eje de la vivencia, tal y cómo la hemos interpretado. Cada pregunta surge de un nivel de abstracción que va abriéndose más hacia un espacio insinuado, apuntando hacia un horizonte: el del nuevo self.

Las respuestas -categorías emergentes-a cada pregunta van configurando un recorrido. Este recorrido queda sintetizado en lo que aparecía como un proceso de descubrimiento (¿qué encuentra?), que conduce a un proceso de transformación (¿adónde lleva?), para que se manifieste el fruto en un proceso unitivo (¿qué emerge?) (Figura 2). Posteriormente, nos percatamos de la resonancia de los procesos que así sintetizamos con la denominación clásica del progreso en la vida espiritual de vía purgativa, vía iluminativa y vía unitiva.

Figura 2. Recorrido Ascendente

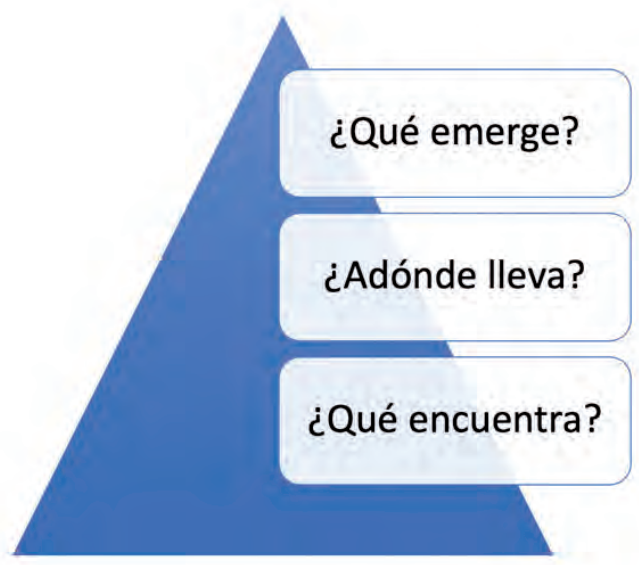

A continuación, se muestra en representación visual las 12 categorías nucleares halladas y los niveles a los que pertenecen (tabla 1). 
Tabla 1. Categorías Nucleares y Niveles del Proceso

\begin{tabular}{l}
\hline ¿Qué encuentra? $\longrightarrow$ ¿Adónde lleva? $\longrightarrow$ Aceptación $\longrightarrow$ Libertad \\
Auto-descubrimiento $\longrightarrow$ EQué emerge? \\
Aumento de la conciencia $\rightarrow$ Crecimiento $\longrightarrow$ Conciencia de unidad \\
cuerpo $\longrightarrow$ Integración $\longrightarrow$ Actuar desde el ser \\
Experiencias unitivas $\longrightarrow$ Cambios en la vida $\longrightarrow$ Proceso unitivo \\
Proceso de descubrimiento $\longrightarrow$ Proceso de \\
transformación
\end{tabular}

\section{Interpretación y Discusión: “Entrar en una Escuela de Vida”}

A continuación, vamos a centrarnos en la interpretación y discusión de las categorías que corresponden directamente a lo que podemos denominar "efectos" de la práctica espiritual, en este caso, del Mes de Ejercicios Espirituales ignacianos. En concreto, las que dan respuesta a las preguntas: ¿Qué encuentra? (figuras 3, 4, 5, 6 y 7), ¿adónde lleva? (figuras 8, 9, 10, 11 y 12), ¿qué emerge? (figura 13).

\section{¿Qué encuentra?}

Figura 3. Primer Nivel de los Efectos: ¿Qué Encuentra?

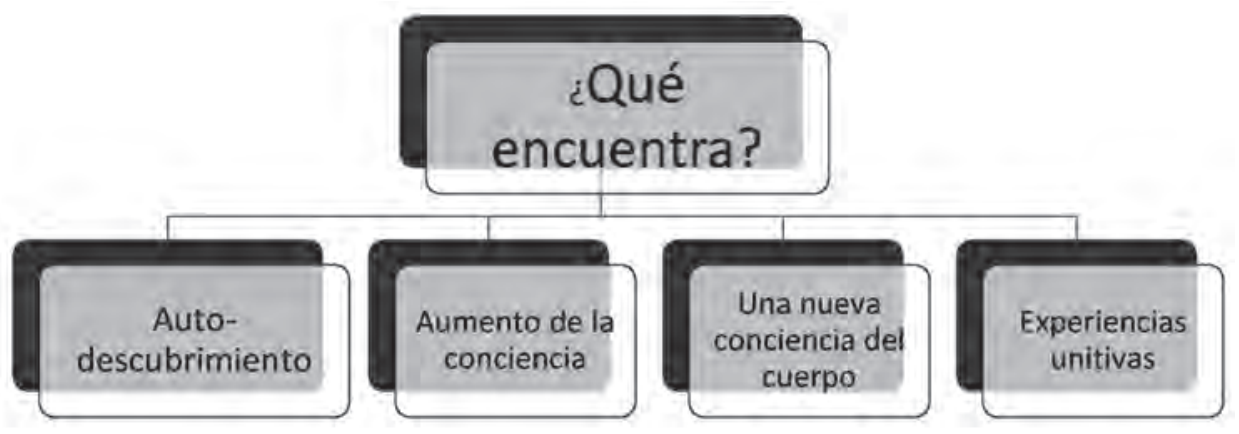




\section{Auto-descubrimiento}

Figura 4. ¿Qué Encuentra?: Auto-descubrimiento

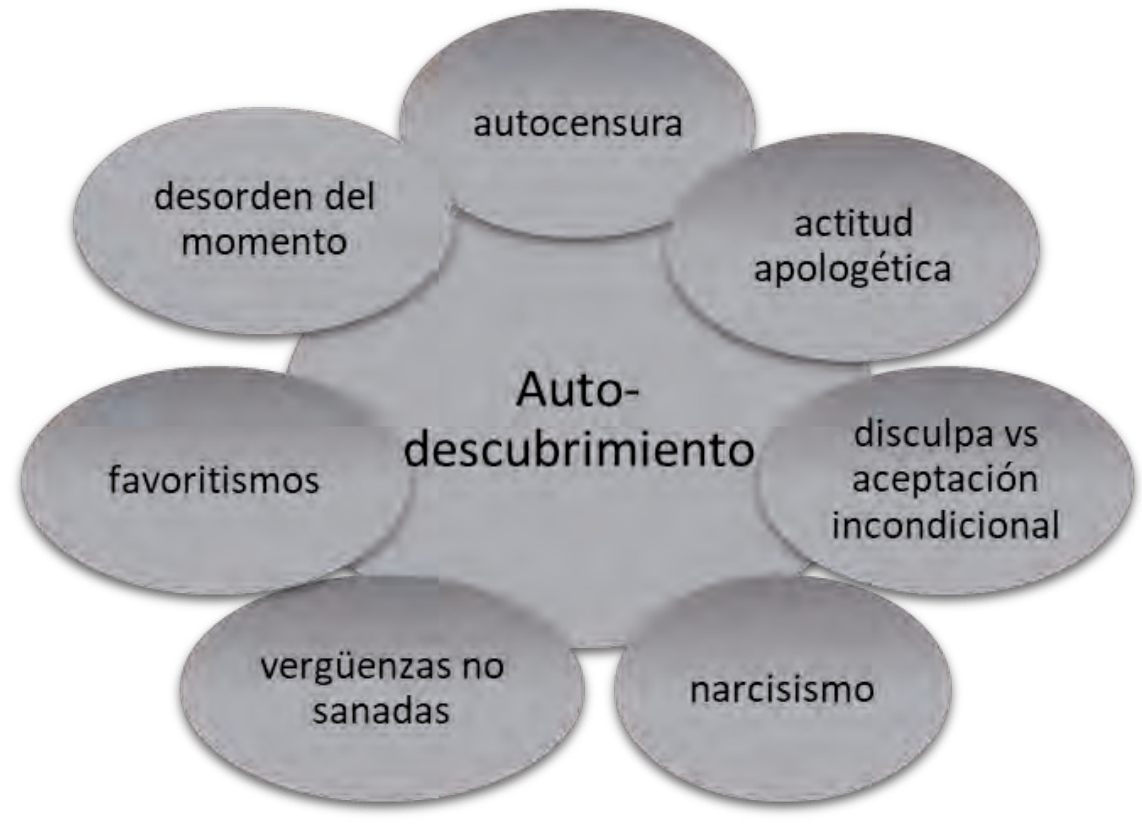

El auto-descubrimiento: tocar la propia realidad.

La experiencia de Ejercicios Espirituales -especialmente en la primera semana- conlleva un descubrimiento de uno mismo en aspectos interiores pendientes de sanar e integrar (sombras), de los que la persona no había tomado consciencia con anterioridad. Ello puede llevarla inicialmente a la vivencia de "topar con una realidad dura de sí misma” (Esther, 22).

Como veremos en el desarrollo de la discusión de lo hallado, a lo largo del recorrido del Mes de Ejercicios Espirituales, la toma de consciencia de la propia realidad irá acompañada de la sanación de dichas heridas y penas, asumiéndolas como parte de la vida, en un proceso de aceptación de los límites -propios y ajenos- mediante el perdón, hacia a uno mismo y a los otros.

Se vive como una apertura a lo nuevo, como una purificación, en la que elementos interiores percibidos como dispersos pasan a ser integrados en una nueva conciencia.

El auto-descubrimiento como paso previo a la sanación.

El descubrimiento -o profundización del conocimiento- de heridas interiores durante la Primera Semana de los Ejercicios Espirituales alcanza no sólo a uno mismo sino también a las heridas del mundo, que dejan huella en la historia, personal y colectiva, y que pueden llegar a ser sentidas por el cuerpo.

Todo ello, emergerá y será considerado a la luz del agradecimiento y la ad- 
miración por la vida y el amor recibidos, en contraste con la constatación de tanta fragilidad y sufrimiento, propios y del mundo.

\section{Aumento de la Conciencia}

Figura 5. ¿Qué Encuentra?: Aumento de la Conciencia

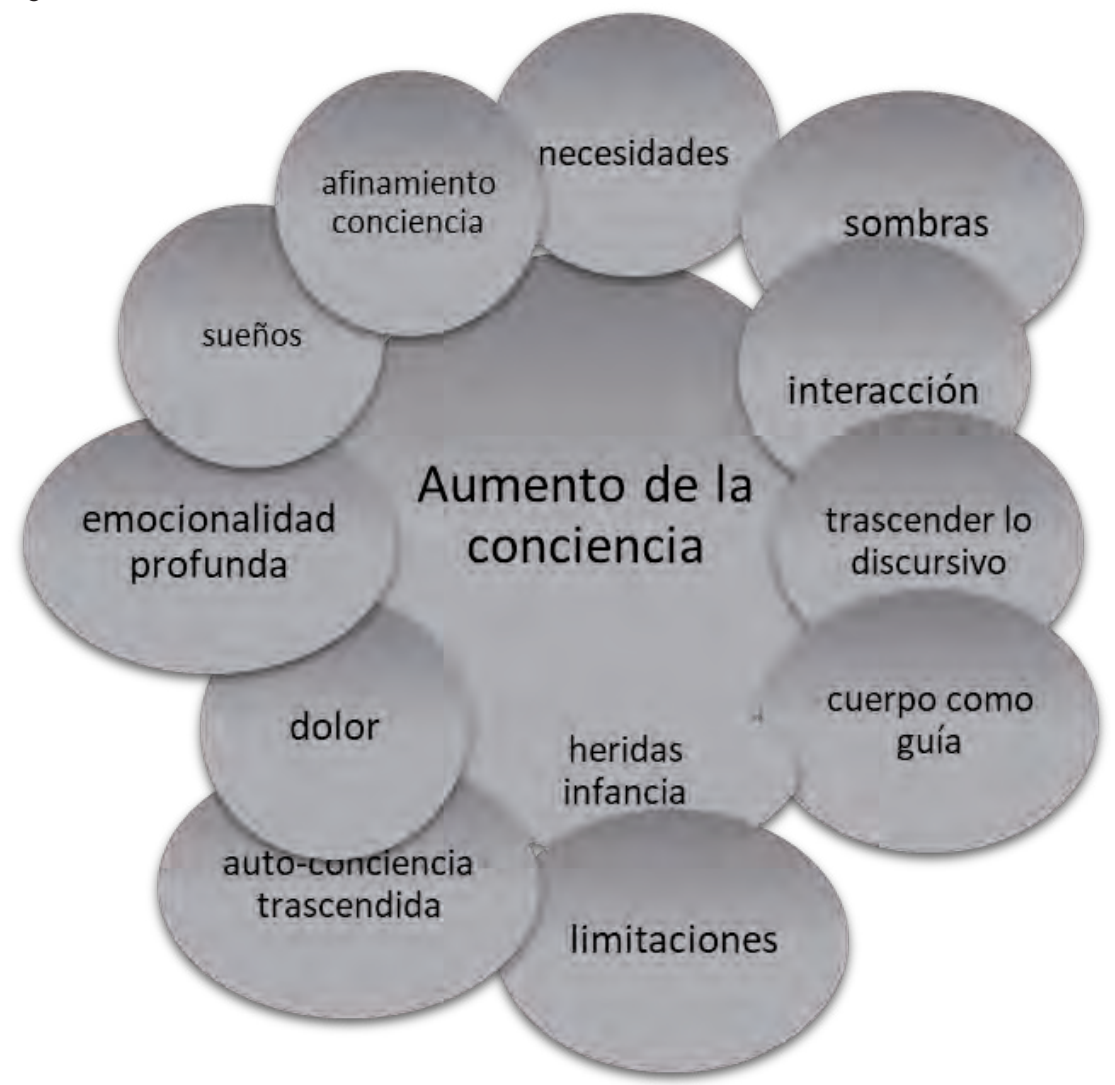

Destacamos el aumento de auto-conciencia que se desprende en las narrativas de los ejercitantes y que ellos resaltan cuando espontáneamente escriben en modo resumen la síntesis de su vivencia. Esta mayor auto-conciencia incluye una mayor consciencia de las propias necesidades; el desvelamiento y la aceptación de las propias sombras; una mayor conciencia de la interacción; una trascendencia de lo discursivo; una conciencia del cuerpo como guía integral; una conciencia agradecida de lo hecho, vivido, sufrido, gustado, aprendido a lo largo de los años; la sanación de heridas cargadas desde la infancia; la aceptación de limitaciones; y la auto-conciencia trascendida. Asimismo, incluimos aquí la conciencia de los sueños, la emocionalidad profunda y el dolor temporal cíclico.

También se añade un matiz, que hemos denominado "afinamiento de la conciencia”, en alusión a esa capacidad de prestar mayor atención y habilidad de dis- 
criminar el modo en que se responde interiormente a un evento exterior, pudiendo ser éste tan sucinto como una palabra. Este afinamiento de la conciencia requiere abrirse a lo nuevo, integrar lo anterior y purificar lo que emerge.

\section{Una Nueva Conciencia del Cuerpo}

Figura 6. ¿Qué Encuentra?: Una Nueva Conciencia del Cuerpo

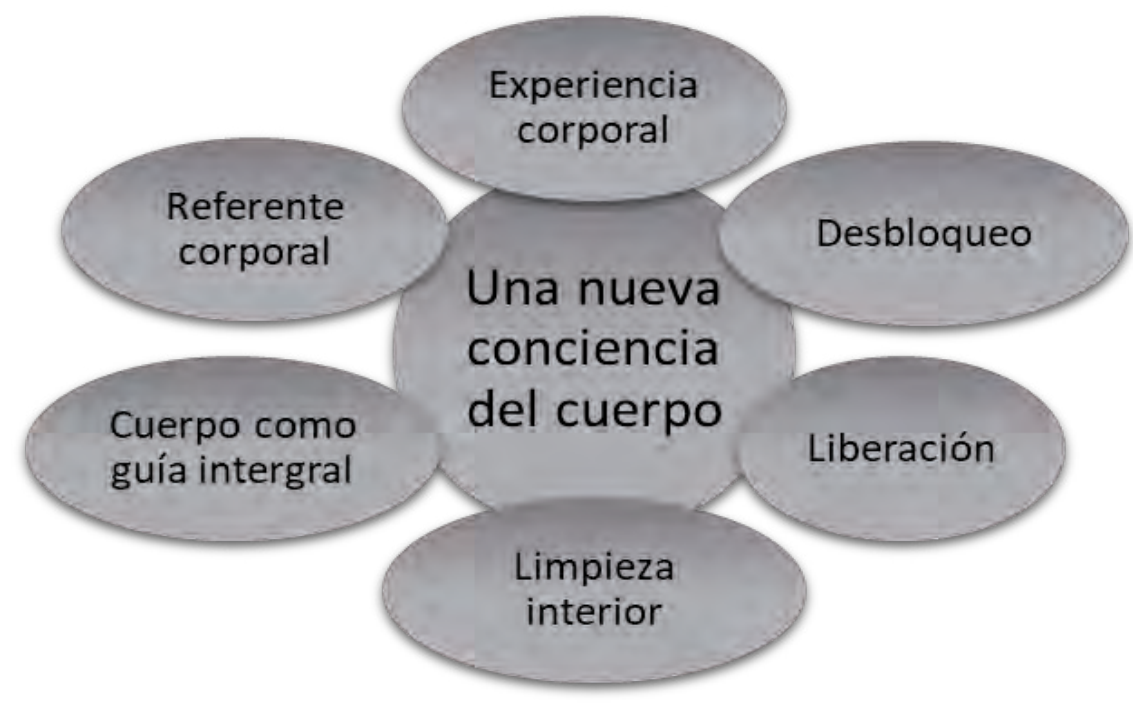

La inclusión de ejercicios físicos como parte de los elementos de apoyo en el proceso representa una novedad para los participantes de esta tanda de Ejercicios Espirituales.

En concreto, la práctica de ejercicios de Chi-Kung es valorada como de ayuda y hasta imprescindible. Aporta conciencia de energía y superación de barreras internas. Se vive como “algo especial” y “sagrado”, y llegan a sentir en la práctica una experiencia muy honda.

Los ejercicios de bio-energética llevaron a la liberación de llanto y tensión acumulada y aportó liberación interior. Cómo se ha explicado anteriormente, estos ejercicios se realizaron durante la primera semana y tenían por finalidad ayudar en el proceso de exploración y liberación de las sombras.

A partir de la narrativa de Esther encontramos una relación entre el aumento y profundización de la auto-consciencia y la sanación de heridas, pasando por la consciencia del cuerpo y el contacto con el dolor físico, no para quedarse en él, sino para abrirse a la comprensión de lo que estaba produciéndolo y sosteniéndolo. La toma de consciencia de todo ello produce en ella liberación y transformación en forma de sanación.

¿Qué liberación/transformación se produce? 
El descubrimiento de esta nueva conciencia que le muestra la auto-aceptación viene acompañado de una nueva clave de interpretación de diversos síntomas físicos y psicológicos, que pone en conexión con lo hallado.

Accede a esta clave interpretativa apoyada en los diversos ejercicios propuestos para aumentar la consciencia y la capacidad de auto-observación sobre el cuerpo y la mente, junto con el trabajo bio-energético y el régimen dietético vegetariano.

El cuerpo es receptáculo de conciencia. Es necesaria la auto-consciencia para acceder más y más a los movimientos que se producen en el cuerpo interior y poder comprender cada vez más sus significados. En ausencia de atención, los pensamientos y emociones negativas van a ir sedimentando sus efectos de manera física en el cuerpo.

\section{Experiencias Unitivas: la Relacionalidad}

Figura 7. ¿Qué Encuentra?: Experiencias Unitivas: la Relacionalidad

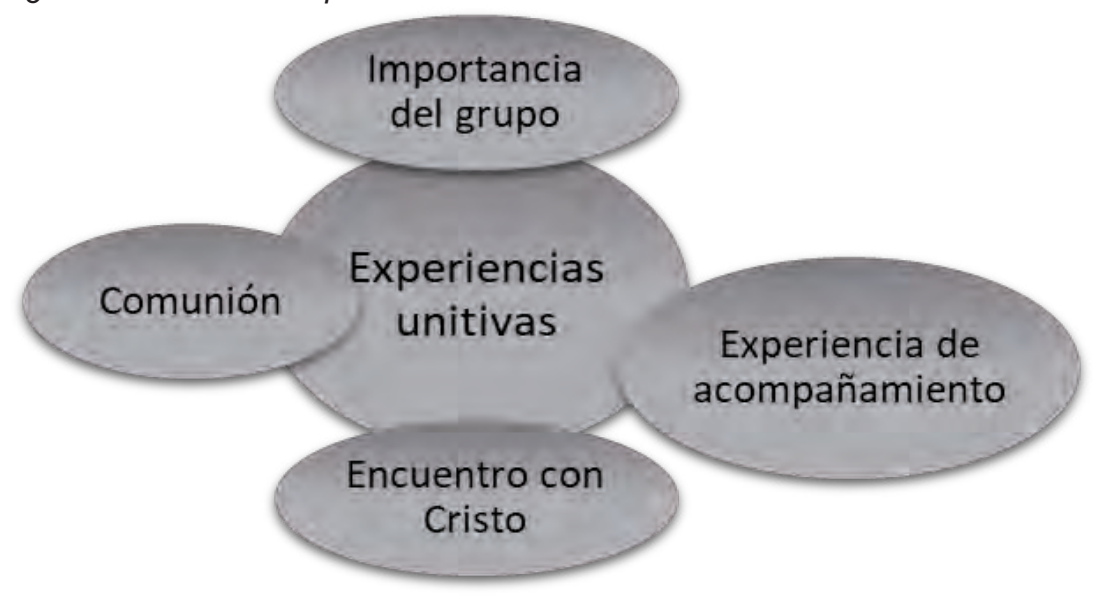

Los ejercitantes van tejiendo una relación muy significativa con el grupoaún en silencio- con el acompañante y, especialmente, con la figura de Jesucristo, centro de los Ejercicios Espirituales. A lo largo del proceso, van adentrándose a la profundidad de la Relación. La relación como configuradora de cambios internos que se manifiestan en cambios en la vida.

En este contexto de retiro, significativamente diferente al habitual y muy específico a este tipo de práctica espiritual, se va accediendo a la relacionalidad, o capacidad para la alteridad, de modos diversos. Se da básicamente a dos niveles diferenciados que, en último término, llevan o cabe llevar, a su integración, desde una conciencia de unidad.

En un nivel, están los otros ejercitantes con quienes no se interactúa a nivel verbal, pero sí que se establece con ellos una relación al compartir el mismo espacio -el centro de espiritualidad - y tiempos muy significativos, no sólo por la duración sino por la profundidad que conlleva el tipo de experiencia que comparten. 
Asimismo, se da una relación con el/la acompañante, en el encuentro de entrevista diaria que, si bien se limita a unos 20 minutos, el contenido y el modo en que ésta se lleva a cabo requiere y configura una alta cualidad relacional.

La relación con el acompañante-como con un terapeuta o coach o tutor-como marco de posibilidad y concreción de la Relación Primordial que se va tejiendo con el Radicalmente Otro, en el que el "antiguo" self pasa también a ser incorporado.

El ejercitante comparte con su acompañante los movimientos interiores que percibe y recibe en los momentos de oración, que en tiempo de Ejercicios Espirituales alcanza la totalidad del día. Ambos están en disposición de escucha interior, y receptivos a la direccionalidad de esos movimientos para así poder discernir el curso de acción. Así mismo, el ejercitante cuenta a través de la persona del acompañante con el contraste conveniente con el principio de realidad, y una guía oportuna en su recorrido de oración.

En otro nivel, la totalidad de los Ejercicios Espirituales está sostenida en el encuentro con Cristo Jesús. Por ello y para ello, las oraciones implican una comunicación con Jesús como modelo de la divinidad humana, así como con otras figuras históricas como María de Nazaret, así como santos y arquetipos de la divinidad propios de la tradición cristiana como son los ángeles y arcángeles, Dios Padre/ Madre, y el Espíritu Santo, hacia quienes los ejercitantes se dirigen buscando luz interior en su proceso de encuentro con lo divino en el camino de plenitud humana y de quienes esperan y confían hallar esa guía.

A lo largo de todo el proceso de Ejercicios Espirituales, se va abriendo y consolidando la profundidad de la relación personal -y al mismo tiempo comunitariade la ejercitante con Cristo Jesús, que la va llevando a una mayor profundidad de relación consigo misma y hacia los demás.

\section{¿A dónde lleva?}

Las categorías anteriormente presentadas llevan a un nuevo nivel de categorización que implica una mayor conceptualización de la vivencia, lo que denominamos un nivel intermedio.

Así, sobre la base del auto-descubrimiento, el Aumento de Conciencia, una Nueva Conciencia del cuerpo y las Experiencias Unitivas, emerge este nuevo nivel con cuatro elementos: Aceptación, Crecimiento, Integración y Cambios en la vida.

Figura 8. Segundo Nivel de los Efectos: ¿Adónde Lleva?

\section{¿A dónde lleva?}

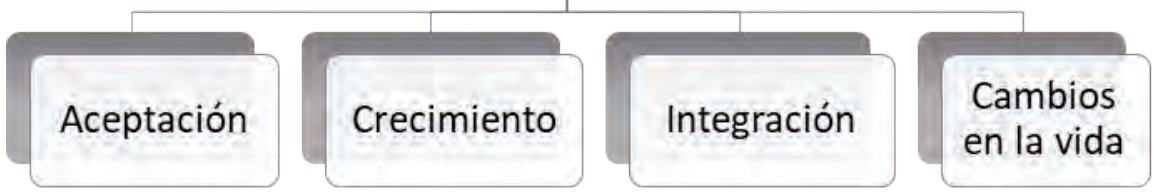




\section{Aceptación}

Figura 9. ¿Adónde Lleva?: Aceptación

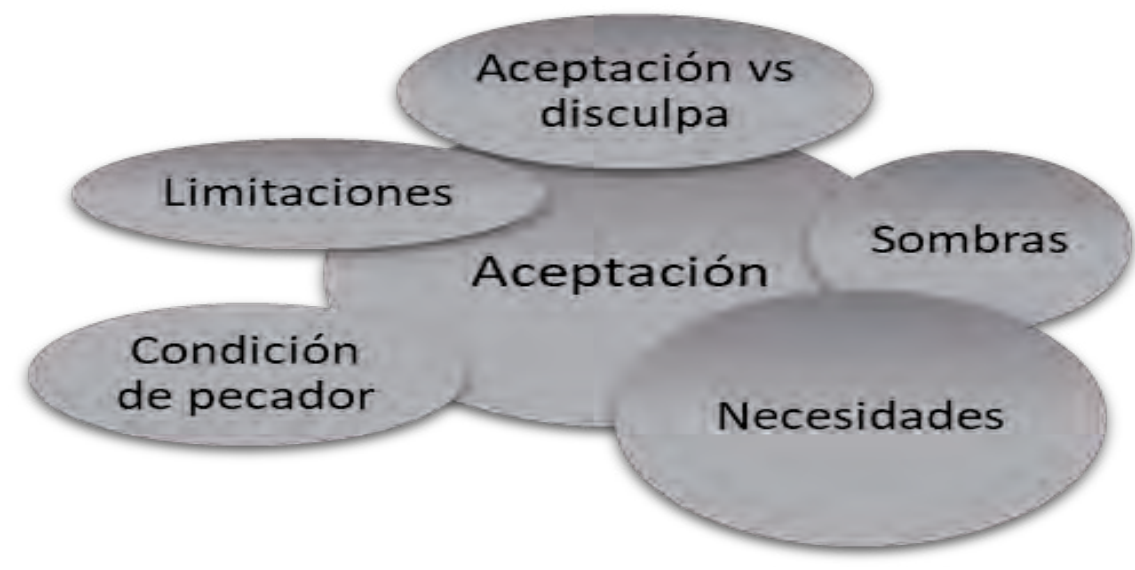

La aceptación como expresión de sanación. La fecundidad del auto-descubrimiento se manifiesta en la aceptación -signo de sanación.

La aceptación discurre por diversos gradientes de profundidad y de amplitud, todos ellos matices de un paisaje interior que ha crecido, pues ahora permite incorporar los aspectos de uno mismo que permanecían ocultos o ensombrecidos, inhibidos, o con los que se estaba en lucha, generando tensión interior y malestar. Expresado en las narrativas incluye la aceptación de los límites propios, las carencias, inseguridades, ignorancias, temores, las necesidades y los errores; las sombras que se reflejan también en la interacción.

La aceptación llega -y lleva consigo- a los otros, también con sus límites, carencias y dificultades.

Serena las emociones negativas y encuadra las reacciones.

Rebaja el perfeccionismo y aleja las exigencias.

Aparta la culpa y atrae el agradecimiento.

Llama a la asunción de sí mismo en clara invitación a responsabilizarse de la propia vida.

Lleva a la aceptación profunda y plena de todo lo que es.

“Todo ser que alienta alaba al Señor. Cada cosa es lo que es, y así está bien” (Verónica, 303). 


\section{Crecimiento}

Figura 10. ¿Adónde Lleva?: Crecimiento

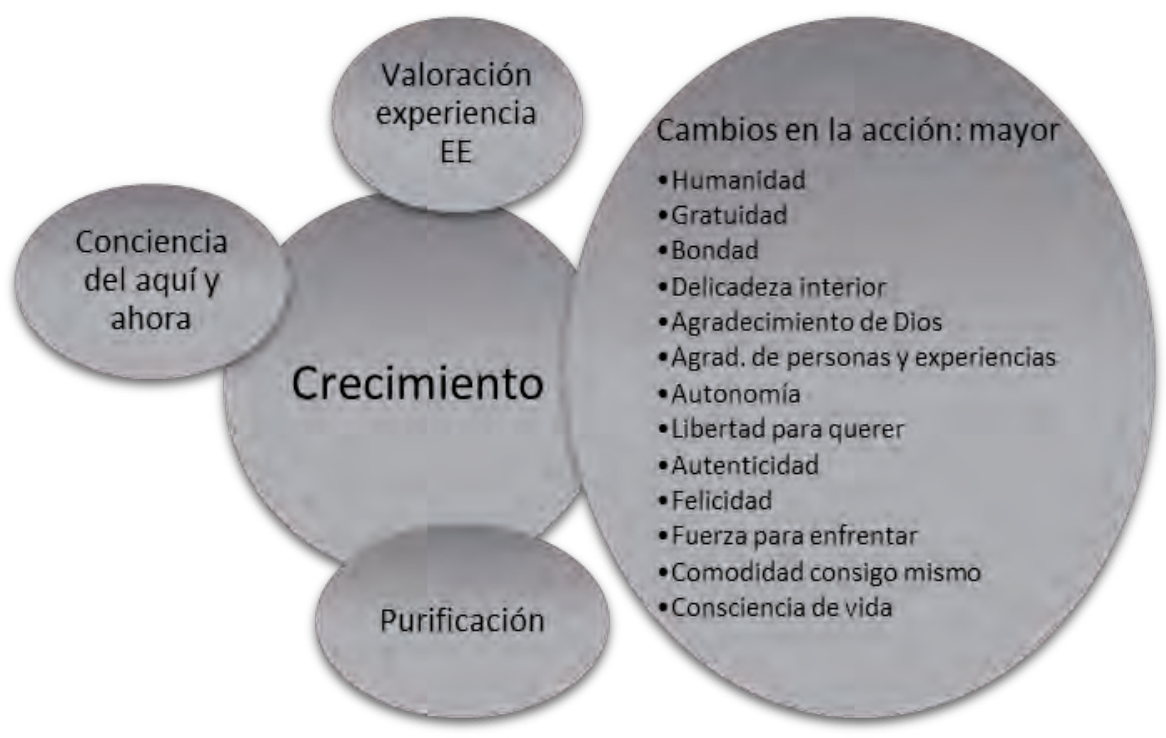

La vivencia de crecimiento queda explicitada en las narrativas de los ejercitantes y asimismo late como fruto de esta experiencia espiritual intensiva. Procede de la valoración global de su experiencia, y de los cambios que sienten se han producido en ellos. Ha conllevado una purificación y una sanación. El aumento de conciencia les permite una mirada de mayor amplitud hacia su propio proceso, que no acaba, y que les permite sentirse en camino de posibilidades abiertas, no limitadas por la edad biológica. Un camino de vida. 


\section{Integración}

Figura 11. ¿Adónde Lleva?: Integración

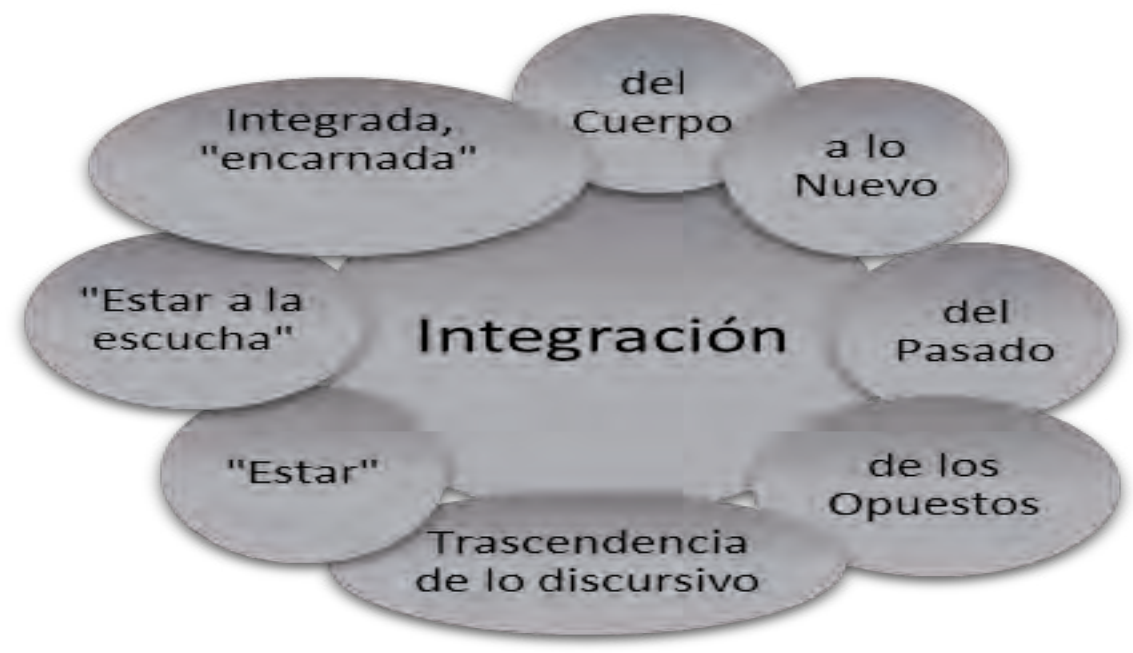

Integración como consciencia de los ecos de la vivencia que son captados y re-producidos en el cuerpo. Entrar en los múltiples niveles de resonancias que se dan en la experiencia consciente. Avanzar en la des-identificación del contenido mental, atravesar la marea emocional, entrar en lo desconocido. De la mano de la confianza. Alinear el interior. Superar la fragmentación.

\section{Cambios en la vida}

Figura 12 ¿Adónde Lleva?: Cambios en la Vida

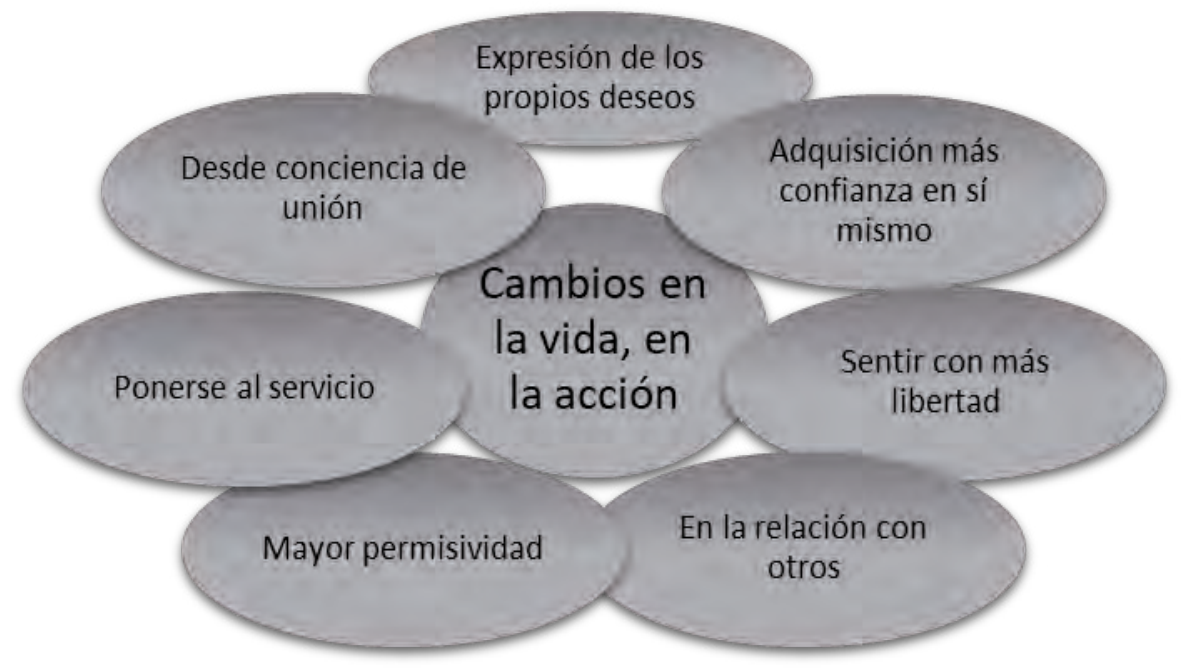


Hemos recogido en esta categoría todos aquellos elementos expresados en las narrativas cuya vivencia conlleva cambios en la acción, en el modo actuar en el mundo. Y son los siguientes: expresión de los propios deseos; adquisición de mayor confianza en sí misma; sentir con más libertad; cambios en la interacción; al servicio de los demás; mayor permisividad; liberación de las ansiedades y dependencias, y acción desde la consciencia de unión.

\section{¿Qué emerge?: El horizonte del nuevo self}

Figura 13 Tercer Nivel de los Efectos: ¿Qué Emerge?

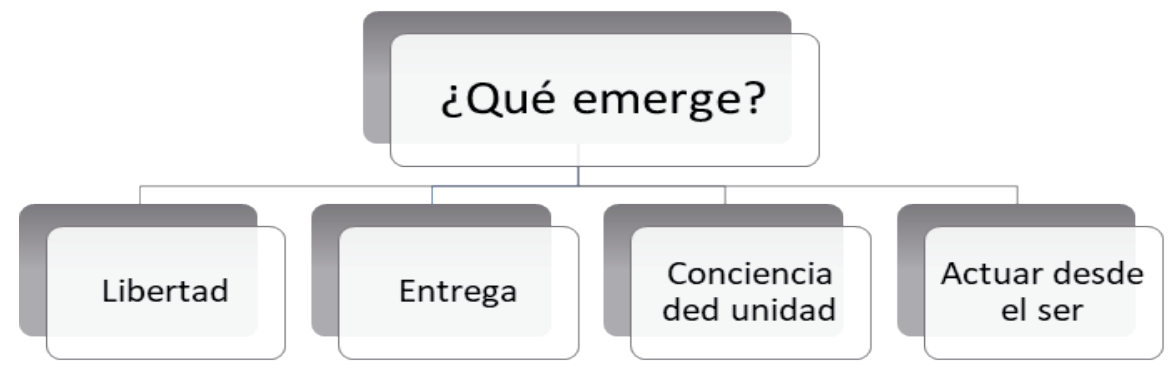

Libertad como el movimiento -impulso genuino y natural de vida- que lleva a que cada uno sea como es sin detrimento de los demás y de lo otro. Implica una plena aceptación propia, de los demás y de las circunstancias tal y como se presentan, que pueden incluir dolor y privaciones. La auto-conciencia de esa aceptación implica un crecimiento que es vaciamiento de las propias expectativas sobre uno, los demás y las circunstancias. Integrar todo ello, en un plano de manifestación física - que es corpórea- y que incluye la relacionalidad con el otro y lo otro, lleva a una conciencia de unidad. Desde esa asunción, emerge un movimiento hacia fuera que incide en el plano exterior dejando cambios, "SIENDO desde Quien le hacer SER" (Esther, 39-41).

Libertad. Con la aceptación de los límites descubiertos y sentidos en uno mismo, en los otros, y en la propia estructura de la realidad, van cayendo las expectativas - construcciones de exigencia a lo que ES.

En ese nuevo espacio, se va hallando una mayor libertad para acoger al otro y para ser acogido. Los límites entre el sí mismo y el otro pierden rigidez.

La consciencia del lugar interior desde el que tomar decisiones se ha ido transformando en una mayor clarificación que supera las imposiciones mentales, que conlleva una nueva atribución de significado a las propias opciones y acciones.

El sentimiento de libertad y la consciencia de gratuidad de todo lo que existe parecen darse muy estrechamente la mano.

Entrega (Servicio). El proceso de los Ejercicios Espirituales de San Ignacio va guiando a la persona hacia el deseo de servir en el mundo, de concretar el sentido de su existencia en una entrega de sí mismo, un sí mismo que ya no es de sí, 
ni es el mismo.

Acción desde el ser: contemplativos en la acción

La acción desde el ser o la forma que va tomando la elección.

La acción de Dios en uno prolongándose en la acción de uno en el mundo. El ser haciéndose forma del Ser sin forma ni medida.

La seducción de Cristo es la seducción del Ser, de ser en plenitud; el Reino (la plenitud) es lo que va surgiendo al obrar desde el ser, al ser desde el obrar.

El horizonte del nuevo self:

"Aquí estoy, Señor,

Toma mi respiración

Que es mi vida entera.

Tú me diste el aliento

Al dejar de respirar,

Y me haces continuamente

Con el soplo de tu Espíritu.

Respírame Tú, corazón con corazón,

Latido con latido, como lo respiras todo.

Todo puede pasar, pero esto me basta. Que en ese todo puedas,

En mí, amar y servir” (Verónica, 808-818).

\section{Ejercicios de Contemplación}

\section{Resultados: Mapa Conceptual y macro-estructuras}

En el estudio de la vivencia de los Ejercicios de Contemplación procedimos a analizar las narrativas del mismo modo que en el estudio del Mes de Ejercicios Espirituales. El mapa conceptual quedó estructurado en base a 8 categorías principales:

1. Resumen camino espiritual previo

2. Práctica espiritual actual

3. Valoración camino interior

4. Efectos de los Ejercicios de Contemplación

5. Proceso de los Ejercicios de Contemplación

6. Vivencias durante los Ejercicios de Contemplación

7. Reflexión sobre la experiencia

8. Cambios atribuidos a la práctica contemplativa

De nuevo, cada línea de texto fue analizada y se crearon las unidades de análisis en base a la coherencia de contenido. Junto a cada una de ellas se indica el número de línea de la narrativa, así como el nombre de la narradora.

En un proceso de síntesis a partir de la elaboración del mapa conceptual, llegamos a identificar 3 macro-estructuras conceptuales que emergían -principalmente de la categoría Vivencias- y que parecen aportar el significado nuclear de la experiencia interior, como la trinidad que abraza y sostiene los cambios que 
mencionan en sus vidas. Éstas son: Atravesar el dolor, Presencia, Ser.

Atravesar el dolor. En el contexto de los Ejercicios de Contemplación el dolor puede presentarse en su forma más elemental como dolor físico por la postura de quietud que se adopta en el banquito de meditación o en el cojín.

Pero el dolor más difícil de afrontar es el dolor interior causado habitualmente por asuntos del pasado pendientes de resolver o de integrar. El encubrimiento de ese conflicto se manifiesta con síntomas físicos de malestar. En momentos prolongados de quietud contemplativa pueden emerger a la conciencia, trayéndolos al presente, sosteniéndolos, y atravesarlos en una nueva atribución de significado; hallando un nuevo lugar en el espacio interior.

Presencia. La presencia: una quietud despierta que atraviesa el campo del malestar.

Que también es presencia de sí misma, en sí misma.

Apertura que trae claridad.

Habita el interior y lo llena de dulzura y compasión.

Presencia inmutable que traspasa todos los estados.

Ser. En la presencia.

Ser reconocida y reconocer-se.

En un camino de plenitud.

Que deja ser.

Que trae cambios.

Y cuya unión con la presencia se vislumbra así...

"Sentir tu propia vibración.

Sentir otra vibración.

Sentir que las dos son la misma.

Sentir una sola vibración.

Una sola presencia que abarca toda la realidad.

Descansar en esa presencia y abandonarse a ella.

Desaparecer y, al mismo tiempo, SER más que nunca.” (Marta, 144-151).

\section{Interpretación y discusión: "Un viaje a mi geografía interior”}

El adentramiento en las narrativas, tras el proceso de análisis y categorización, fue llevando a identificar una clara comunalidad de vivencia tal y cómo quedaba reflejada por sus autoras e interpretada en el mapa conceptual.

El árbol-eje de la vivencia de los Ejercicios Espirituales pasaba a ser aquí una melodía. Cada narrativa parecía aportar los acordes que resonaban en un mismo armónico.

Pusimos palabras a esa melodía común, surgiendo una narrativa única. Inclusiva. Las vivencias narradas se asemejaban hasta el punto de poderlas unificar en una sola. En un relato de viaje común....

“Un viaje a mi geografía interior” (Begoña, 6). 
1. Lugar de partida

2. Equipaje

3. Recorrido

4. Imágenes

5. Sensaciones

6. Tropiezos, hallazgos y encuentros

7. Recuerdos de lo vivido

8. ¿Cómo es ahora?

A efectos de este artículo, por motivos de espacio, reproducimos el último punto de la narrativa única interpretada, la que describe propiamente los "efectos" de los 8 días de Ejercicios Contemplativos, titulada “¿Cómo es ahora?”

\section{¿Cómo es ahora?}

A nivel interior, vive la práctica contemplativa como un proceso de descubrimiento. Al que llegó por saturación de su trabajo anterior de crecimiento personal, que incluía diversas experiencias. Ese tramo de su etapa anterior la llevó a intuir y a aspirar hacia algo mucho mayor. En este su nuevo camino halló el modo de trascender la carga personal: entrar y habitar el silencio. Ahí descubrió la ausencia de interpretación y de auto-juicio. Una aceptación plena que le permite ser tal como es. Que le muestra una nueva visión sobre la calidad de ser. Encuentra -y se encuentra- en un camino de plenitud y verdad.

Esto la lleva a superar la necesidad de buscar fuera, confiada en eso mucho mayor que ha hallado, que lo siente interno, muy propio y muy bueno. Y descansa en eso.

Se da cuenta que, en su movimiento externo desde ese interior, atiende ahora a lo pequeño, a lo aparentemente insignificante, pues sabe que lo importante, lo valioso, lo esencial no está fuera. Su deseo de estar acorde con esta armonía interior la lleva a hacer las cosas bien-despojadas de perfeccionismo-, a hacerlas con gusto, con una dedicación más atenta. Se da cuenta que la lleva a más y mejor entrega.

Sigue su verdadera guía, a la que reconoce porque le aclara la mirada, no juzga ni critica, la deja ser. Le muestra la sustancia y la belleza de su vida.

Se siente íntima y profundamente acompañada desde su propio interior. Sabe de quién se fía. Y así, recibe fuerza y serenidad para afrontar cambios y retos importantes en su vida.

En su relación con los otros, percibe con mayor sensibilidad las necesidades de los demás. Su generosidad ha crecido y también su alegría.

Este camino ha conllevado para ella una acción liberadora, que le permite relativizar las cosas y actuar con distancia emocional. Brota así un mayor compromiso en ella y desde ella; un mayor equilibrio y paz.

Los pasos en este camino imprimen una visible huella de aceptación, de los propios procesos y de los demás.

En ese andar despojado de imposiciones a la realidad puede ver la perfección 
de cada día.

\section{Conclusiones: Las Raíces}

Existe una dimensión en el ser humano, común a todos, que lo vincula a todo, y que al mismo tiempo le otorga su esencialidad y singularidad. Es la dimensión más honda que subyace en la realidad que lo constituye. Es la dimensión espiritual o trascendental.

En un modelo integrador del ser humano cabe incluir y explicitar esta dimensión espiritual en el avance de la comprensión y facilitación de los procesos óptimos de desarrollo humanos.

Una psicología con vocación de servicio a la persona en su totalidad y que tiene en consideración todo el ámbito de la experiencia humana, está llamada a incluir en sus planteamientos de estudio y de praxis, de investigación y de aplicación, dicha dimensión espiritual.

En la actualidad, podemos presentar dos conceptos, dos constructos, a través de los cuales se está acercando este postulado al campo de la psicología. Uno de ellos, el Mindfulness, (traducido como atención o conciencia plenas) ha llegado directamente de la mano de la espiritualidad reglada, en concreto procedente del budismo, y está hallando su lugar principalmente en el terreno de la psicoterapia.

El otro, la Inteligencia Espiritual, está siendo desarrollado en el contexto de la personalidad, con una clara proyección hacia ámbitos aplicados como la educación.

\section{Hacia una Psicología Contemplativa}

En la introducción del Mindfulness en ámbitos clínicos, éste parece haber quedado circunscrito a la aportación pionera del médico y practicante budista Jon Kabat-Zinn, quien, a partir de la incorporación de prácticas de atención plena en pacientes con dolor crónico desarrolló el programa de Reducción del Estrés Basado en la Atención Plena (MBSR: Mindfulness Based Reduction Program). Al integrar su dedicación profesional en el campo de la interacción mente-cuerpo con su experiencia en la práctica de meditación abrió un nuevo ámbito de exploración de posibilidades al aplicar algunas técnicas de las enseñanzas budistas en situaciones clínicas.

Mindfulness es algo difícil de definir. Lo que resulta muy notorio -y sugerente de reflexión- es que un término directamente procedente de una tradición de sabiduría espiritual se encuentre en la actualidad tan extensamente introducido en el ámbito académico y clínico.

Ciertamente, nos hallamos ante un nuevo modelo en el que la sabiduría contenida y custodiada por ramas milenarias de conocimiento profundo del ser humano parece haber penetrado el árbol de la ciencia, en un encuentro llamado a dar fruto.

Quizás es ésta una buena oportunidad para abrir aún más el espacio de acogida y de hacer aún más porosa la corteza del árbol para dejar que las ciencias humanas, sociales y de la salud se impregnen de la savia procedente de los densos 
bosques de las tradiciones contemplativas que generosamente viene a derramarse para llegar a suelo común, para nutrir a toda la especie, pasando a través del árbol haciéndolo así fecundo.

Un árbol de conocimiento que se abre a estudiar aquello que recibe, humildemente dispuesto a entrar "en terreno sagrado" y ofrecer lo mejor de sí para acercarse a enseñanzas que albergan modos, métodos y prácticas para llevar al ser humano a la mejor versión de sí mismo.

En concreto, una psicología tendida hacia el estudio de las prácticas y ejercicios que abren la dimensión contemplativa y que fundamenta a las tradiciones de sabiduría.

Una psicología que contempla, y desde ahí, actúa.

Kabat-Zinn (1994) sintetiza mindfulness como prestar atención de una manera especial: intencionadamente, en el momento presente, y sin juzgar.

En nuestro contexto, Vicente Simón (2010) lo define como la capacidad humana universal y básica, que consiste en la posibilidad de ser conscientes de los contenidos de la mente momento a momento.

Esta capacidad requiere práctica, y una práctica paciente. Una práctica que empieza observando dentro, volviendo la mirada hacia sí. Quizás lo que más la diferencia de cualquier otro tipo de práctica es la actitud fundamental que la acompaña: la aceptación. No hay un lugar dónde ir, ni un estado determinado que alcanzar. Tan "sólo" estar. Estar con todo lo que va emergiendo en la conciencia, en tiempo de quietud meditativa, para ir extendiéndolo al momento-a momento interactivo con el otro, los otros, lo otro. Ampliando el sí mismo en un horizonte común.

Una cualidad de estar que va configurando un modo de ser y de relacionarse.

Una capacidad de irse haciendo más consciente que puede ser ejercitada mediante prácticas que modifican la capacidad atencional, pero que está lejos de confinarse a un espacio cognitivo. Abrirse a mayor conciencia conlleva abrir el corazón.

Posiblemente a eso se deba los efectos beneficiosos sobre la salud física, emocional y mental de las personas a quienes se les enseña a practicar en contextos clínicos supervisados profesionalmente. Profesionales que, a su vez, han recibido beneficios de dicha práctica y, en esa medida y de ese modo, pueden acercarla para ayudar a aliviar diversos modos de sufrimiento y acompañar procesos de cambio hacia el crecimiento. La literatura sobre estos efectos en ámbitos clínicos se extiende en la actualidad a, literalmente, miles de trabajos científicos, situación que la coloca más allá del ámbito de este artículo, tanto por extensión, como por contenido.

\section{Ampliando los Márgenes de la Inteligencia: La Inteligencia Espiritual}

El modelo de inteligencias múltiples enunciado por Howard Gardner (1998) amplió sustancialmente el escurridizo y delicado constructo de inteligencia, también explorado en sus diferentes aristas por otros investigadores. Goleman (1996) afinó aún más la aproximación al introducir el concepto de inteligencia emocional 
que basó en la inteligencia intra-personal y la inter-personal. El paso decisivo a no confinar la inteligencia a unas habilidades útiles pero restringidas, abrió nuevas consideraciones sobre la potencialidad del ser humano en sus diferentes facetas.

Ha sido recientemente que se ha introducido en el ámbito de la investigación el constructo de inteligencia espiritual. Si un acuerdo sobre qué significa espiritualidad resulta difícil dado las múltiples connotaciones que implica, adjetivarlo junto a la inteligencia puede parecer en exceso elusivo a la psicología académica. Y al mismo tiempo, denota la constatación de una realidad y el deseo de acercarse más a ella (para una perspectiva amplia y crítica, véase Emmons, 2000).

En el giro de siglo que han sido presentadas diversas definiciones de Inteligencia Espiritual (Zohar y Marshall, 2000, y en nuestro contexto Torralba, 2010) en un movimiento sincrónico con un aumento del interés hacia la espiritualidad desligada de un marco confesional en una amplio sector de la sociedad occidental.

En un excelente ensayo publicado en el Journal of Humanistic Psychology, Frances Vaughan (2002) se adentra a indagar qué es la Inteligencia Espiritual, desde la interconexión entre la psicología y la espiritualidad a partir de su propia experiencia personal y profesional como terapeuta humanista, y destaca como ésta puede desarrollarse con la práctica.

En comunicaciones anteriores (Puche et al., 2012; Puche y Botella, 2013), expusimos un trabajo preliminar en el que exploramos la relación entre inteligencia emocional (Salovey y Mayer ,1989) y espiritual, siendo ésta una línea de investigación en la que esperamos publicar más extensamente en breve.

En paralelo a nuestra primera presentación en contexto científico, se publicó un artículo poniendo en relación los dos constructos de Inteligencia Emocional y Espiritual (King et al., 2012), que nos confirmó el interés de dicha exploración.

\section{Tendiendo Puentes}

Queda mucho terreno por explorar para ver de qué modos la psicología tiende puentes hacia la comprensión profunda de la naturaleza espiritual del ser humano y de los contextos necesarios para que ésta florezca y sea fecunda.

En este nuevo marco, resulta alentador el interés científico actual de crear campos de investigación inter-disciplinarios sobre la vivencia en primera persona de diversas prácticas espirituales consolidadas, así como de los efectos que produce en la persona y, en último término, en los cambios que esto trae a la sociedad.

Allan Wallace (2009) denomina “científicos contemplativos" a la generación actual de profesionales formados tanto en las ciencias de la mente como en el ejercicio de las prácticas contemplativas, así como en el estudio de las teorías que las enmarcan.

Las iniciativas de encuentros científicos multi-disciplinarios como las promovidas por el Mind and Life Institute son una buena muestra de este giro hacia una aproximación contemplativa de la ciencia. Comunicaciones científicas sobre prácticas contemplativas se entrelazan con momentos de práctica conjuntamente 
realizada por los investigadores participantes en el encuentro. En palabras de Wallace: En el futuro, la combinación de la investigación científica objetiva dirigida hacia el exterior, con la investigación contemplativa dirigida hacia el interior, abrirá la posibilidad de una comprensión mucho más profunda de la naturaleza y del potencial de la consciencia. (Wallace, 2009, p. 65)

\section{Reflexiones Finales}

La vivencia espiritual. Narrada en primera persona. A partir de dos prácticas espirituales regladas, dos métodos, dos caminos conductivos de vivencia interior profunda. Que producen cambios, en el modo de comprenderse a sí mismo, a los otros y a lo otro. Cambios interiores que llevan a cambios en el modo de vivir. En el modo de asumir y asumirse. Cambios que apuntan a un horizonte de crecimiento hacia la plenitud. Cambios que se inician en el individuo y tocan la realidad que lo rodea. El desarrollo pleno de un individuo -la asunción plena en uno- no empequeñece a nadie, nos agranda a todos.

Un horizonte de plenitud que está aquí y ahora. Inmerso en lo cotidiano, en la dificultad y en la desidia, en la ambición y en la traición, en la ruptura y el desengaño; en el dolor y el sufrimiento. Propio y del mundo. Pues no hay diferencia. No hay límite que lo separe. Está en uno y está en todos. En todo. Esperando ser reconocido, mostrado y compartido.

Recibido, asumido y entregado.

Esperando...

Esperando que el canto del canario que enmudece y se desvanece en la mina de carbón sea suficiente signo.

Signo suficiente para movilizar. Para preguntarnos qué es lo que está asfixiando la vida. Qué toxicidad nos aparta de la pureza del aliento que nos sostiene.

Un respirar que está aquí y ahora. Esperando ser inhalado y exhalado. En las formas que corresponden a cada tiempo, a cada momento. A este ahora. En este aquí.

\section{Referencias}

Almendro, M. (1995). Psicología y Psicoterapia Transpersonal. Kairós.

Braud, W. y Anderson, R. (1998). Transpersonal research methods for the social sciences : honoring human experience. Sage Publications.

Charmaz, K. (2008). Grounded Theory. En J. A. Smith (ed.), Qualitative Psychology. A practical Guide To Research Methods (2 $2^{\text {a }}$ d., pp. 81-110). Sage Publications.

Emmons, R. A. (2000). Is Spirituality an Intelligence? Motivation, Cognition, and the Psychology of Ultimate Concern. International Journal for the Psychology of Religion, 10(1), 3-26. http://doi.org/10.1207/ S15327582IJPR1001_2

Gardner, H. (1998). Inteligencias múltiples. Paidós.

Goleman, D. (1996). Inteligencia Emocional. Kairós.

Groff, S. (1986). Psicología Transpersonal: nacimiento, muerte y trascendencia en psicoterapia. Kairós.

Groff, S. (2000). La psicología del futuro. Lecciones de la investigación moderna de la consciencia. La Liebre de Marzo. 
Grossman, P., Niemann, L., Schmidt, S. y Walach, H. (2004). Mindfulness-based stress reduction and health benefits. A meta-analysis. Journal of Psychosomatic Research, 57, 35-43. https://doi.org/10.1016/S00223999(03)00573-7

Hayes, S. (2004). Acceptance and Commitment Therapy and the New BehaviorTherapies: Mindfulness, Acceptance, and Relationship. En S. C. Hayes, V. M. Follete y M. M. Linehan (eds.), Mindfulness and Acceptance. Expanding the Cognitive-Behavioral Tradition (pp. 1-29). Guilford.

Hayes, S. C., Luoma, J. B., Bond, F. W., Masuda, A. y Lillis, J. (2006). Acceptance and commitment therapy: model, processes and outcomes. Behaviour Research and Therapy, 44(1), 1-25. http://doi.org/10.1016/j. brat.2005.06.006

Hayes, S. C., Strosahl, K. D. y Wilson, K. G. (1999). Acceptance and commitment therapy: An experiential approach to behavior change. Guilford.

Herrero, O. (2003). De la ausencia de significado al significado de la ausencia: la reconstrucción discursiva de los procesos de duelo en un caso de psicoterapia. [Tesis doctoral, Universidad Ramon Llull (España)].

Jalics, F. (1998). Ejercicios de Contemplación. Sígueme.

Kabat-Zinn, J. (1994). Where ever you go, there you are. Hyperion.

Kabat-Zinn, J., Massion, A. O., Kristeller, J., Peterson, L. G., Fletcher, K. E., Pbert, L., Lenderking, W. R. y Santorelli, S. F. (1992) Effectiveness of a meditation-based stress reduction program in the treatment of anxiety disorders. Am J Psychiatry, 149(7), 936-943. https://doi.org/10.1176/ajp.149.7.936

King, D. B., Mara, C. A. y De Cicco, T. L. (2012). Connecting the spiritual and emotional intelligences: Confirming an intelligence criterion and assessing the role of empathy. International Journal of Transpersonal Studies, 31(1), 11-20. http://dx.doi.org/10.24972/ijts.2012.31.1.11

Lajoie, D. H. y Shapiro, S. L. (1992). Definitions of transpersonal Psychology - the first twenty three years. The Journal of Transpersonal Psychology, 24(1), 79-98.

Leigh, J., Bowen, S. y Marlatt, G. A. (2005). Spirituality, mindfulness and substance abuse. Addictive Behaviors, 30(7), 1335-1341. http://doi.org/10.1016/j.addbeh.2005.01.010

Lowen, A. (1994). La espiritualidad del cuerpo: bionergética, un camino para alcanzar la armonía y el estado de gracia. Paidós.

Maslow, A. (1972). El hombre autorrealizado. Hacia una psicología del ser. Kairós.

Puche, A. y Botella, L. (2013, Octubre). The Emergence of Emotional Intelligence and Spiritual Sensitivity in an Intensive Spiritual Program [Presentación de Póster]. Mind and Life Europe Symposium for Contemplative Studies, Berlin.

Puche, A., Botella, L. y Gallifa, J. (2012, Noviembre). Desarrollo de la Inteligencia Emocional a Través de un Programa Intensivo Espiritual: Estudio de Caso [Comunicación Oral]. $1^{\mathrm{er}}$ Congreso Nacional de Inteligencia Emocional, Barcelona, España.

Ramel, W., Goldin, P. R., Carmona, P. E. y McQuaid, J. R. (2004). The effects of mindfulness meditation on cognitive processes and affect in patients with past depression. Cognitive Therapy and Research, 28(4), 433-455. http://doi.org/10.1023/B:COTR.0000045557.15923.96

Salovey, P. y Mayer, J. D. (1989). Emotional Intelligence. Imagination, Cognition and Personality, 9(3), $185-211$. http://doi.org/10.2190/DUGG-P24E-52WK-6CDG

Scherer-Dickson, N. (2004). Current developments of metacognitive concepts and their clinical implications: mindfulness-based cognitive therapy for depression. Counselling Psychology Quarterly, 17(2), 223-234. http://doi.org/10.1080/09515070410001728253

Schreurs, A. (2004). Psicoterapia y espiritualidad. La integración de la dimensión espiritual en la práctica terapéutica. Desclée de Brower.

Segal, Z. V., Williams, J. M. y Teasdales, J. D. (2002). Mindfulness-based cognitive therapy for depression. Guilford.

Simón, V. (2010). Mindfulness y psicología: presente y futuro. Revista Quadrimestral Del Col·legi Oficial de Psicòlegs de La Comunitat Valenciana, 100, 162-170.

Teasdales, J. D., Segal, Z. V., Williams, J. M., Ridgeway, V., Soulsby, J. y Lau, M. A. (2000). Prevention of relapse/recurrence in major depression by mindfulness-based cognitive therapy. Journal of Consulting and Clinical Psychology, 68, 615-623. https://doi.org/10.1037/0022-006X.68.4.615

Torralba, F. (2010). Inteligencia Espiritual. Plataforma.

Vaughan, F. (2002). What is Spiritual Intelligence ? Journal of Humanistic Psychology, 42(2), 16-33. https://doi. org/10.1177\%2F0022167802422003

Wallace, B. A. (2009). Mente en Equilibrio. La meditación en la ciencia, el budismo y el cristianismo. RigdenInstitut Gestalt.

Wellwood, J. (2002). Psicología del despertar. Budismo, psicoterapia y transformación personal. Kairós.

Wilber, K. (1989). El proyecto Atman. Una visión transpersonal del desarrollo humano. Kairós. 